Психология. Журнал Высшей школы экономики.

2010. T. 7, № 3. С. 81-88.

\title{
РЕФЛЕКСИЯ КАК УСЛОВИЕ ОВЛАДЕНИЯ ИНТЕЛЛЕКТУАЛЬНЫМИ ОПЕРАЦИЯМИ
}

\author{
Л.А. ДА СИЛВА
}

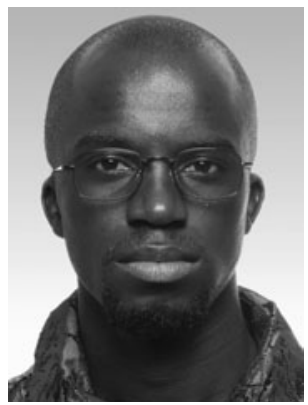

Ливио Антонио да Силва (Livio Antonio Da Silva) - аспирант Московского педагогического государственного университета. Область научных интересов - педагогическая психология, психология способностей, возрастная психология и психология развития. Контакты: livio-a@mail.ru

\section{Резюме}

В статье на основе экспериментальных данных показывается, что успешное освоение интеллектуальных операций зависит от их рефлексии обучаемым. В свою очередь успешность рефлексии определяется рефлексивностью как личностным качеством.

Ключевые слова: рефлексия, рефлексивность, интеллектуальные операции, мышление, интеллект.

В настоящей работе исследуется роль развития рефлексии интеллектуальных операций младшими школьниками в процессе их освоения. Работа выполнена в русле теории способностей В.Д. Шадрикова (Шадриков, 2006, 2007), определяющего способности в трех измерениях: индивида, субъекта деятельности и личности. Способности человека как индивида отражают их природную (биологическую) сущность. Они сформировались для обеспечения выживания человека в естественных природных условиях. Способности человека как субъекта деятельности развиваются на базе природной способности индивида путем достраивания их интеллектуальными операциями. Способность человека как личности формируется на базе способности индивида и субъекта деятельности путем постановки последних под контроль нравственных норм.

Цель работы: проверить гипотезу о наличии связи между рефлексией интеллектуальных операций и успешностью освоения интеллектуальных операций.

Для исследования были выбраны учебный предмет «математика» (авторы учебника М.И. Моро, С.И. Волкова) 
и следующие интеллектуальные операции мышления: анализ, синтез, абстрагирование, сравнение, обобщение, классификация. Исследование проводилось с учащимися третьего класса школы № 1271 г. Москвы.

В ходе проведения работы было организовано 2 серии исследований. В первой серии изучалась связь уровня развития рефлексии и уровня освоения интеллектуальных операций. Во второй серии исследовалась связь рефлексивности как личностного качества с рефлексией интеллектуальных операций и уровнем владения данными операциям.

В первой серии для определения уровня рефлексии интеллектуальных операций была разработана авторская методика. Ее суть заключается в том, что после выполнения серии заданий испытуемым задаются вопросы, позволяющие определить, насколько осознанным было выполнение данных заданий и как в этом процессе были задействованы рефлексивные механизмы. Ответы оцениваются по 4-балльной шкале. Суммарное количество баллов, которое набирает ученик, характеризует уровень его рефлексии интеллектуальных операций.

Для каждой операции были разработаны отдельное задание и вопросы на рефлексию, которые задавались после решения задания. Задания подобраны с учетом имеющихся знаний, навыков и умений учащихся.

Особенности проведения данной методики описаны ниже.

Деятельность: групповая по 3-4 человека.

Раздаточные материалы: бланки с математическими заданиями по числу испытуемых.
Инструкция испытуемым: «Выполните письменно 6 заданий, написанных на этой карточке. После того как вы все сделаете, вам зададут несколько вопросов. Время решения не ограничено».

Ход эксперимента: экспериментатор раздает группе в 3-4 человека бланки с заданиями. После выполнения работы экспериментатор проверяет задания. Если они выполнены неправильно - задания выдаются вновь. Затем каждому ученику задаются вопросы на рефлексию. Ответы фиксируются на специальных бланках. На основе полученных ответов выставляются итоговые баллы.

Обработка результатов: баллы, отражающие уровень рефлексии каждой интеллектуальной операции, суммируются и заносятся в сводную таблицу.

Максимальное число баллов для каждого ученика за все 6 заданий составляет 24 балла (или 100\%). Максимальное количество баллов по каждой операции - 72 балла (или $100 \%)$.

Результаты первой серии представлены в таблице 1.

В последних колонках напротив имени каждого ученика приведены показатели рефлексивности интеллектуальных операций: количество баллов, набранных испытуемым по всем операциям, и процент от максимального количества баллов по 6 заданиям. На основании полученных результатов можно сделать следующие выводы:

1) испытуемые в разной мере осознают конкретные интеллектуальные операции - от 0 до 4 баллов;

2) испытуемые в различной мере характеризуются рефлексией по 
Таблища 1

Рефлексия интеллектуальных операций

\begin{tabular}{|l|c|c|c|c|c|c|c|c|}
\hline \multicolumn{1}{|c|}{ Имя Ф. } & Ан & $\mathbf{C}$ & $\mathbf{A б}$ & $\mathbf{C p}$ & $\mathbf{~ О б}$ & $\mathbf{K}$ & $\begin{array}{c}\text { Всего } \\
\text { баллов }\end{array}$ & Всего \% \\
\hline Арсений А. & 4 & 3 & 4 & 4 & 3 & 4 & 22 & $91 \%$ \\
\hline Денис В. & 2 & 3 & 3 & 2 & 3 & 3 & 16 & $67 \%$ \\
\hline Лейла Г. & 4 & 3 & 4 & 3 & 2 & 2 & 18 & $75 \%$ \\
\hline Люба Г. & 4 & 3 & 2 & 3 & 4 & 3 & 19 & $79 \%$ \\
\hline Дарина Д. & 4 & 3 & 3 & 4 & 4 & 4 & 20 & $83 \%$ \\
\hline Дуня 3. & 3 & 4 & 3 & 3 & 3 & 2 & 18 & $75 \%$ \\
\hline Габор К. & 4 & 4 & 4 & 3 & 4 & 4 & 23 & $96 \%$ \\
\hline Вахтанг К. & 0 & 2 & 0 & 1 & 2 & 3 & 8 & $33 \%$ \\
\hline Денис К. & 0 & 2 & 0 & 1 & 2 & 0 & 5 & $21 \%$ \\
\hline Аня К. & 4 & 4 & 3 & 4 & 4 & 4 & 23 & $96 \%$ \\
\hline Алеша М. & 3 & 2 & 1 & 3 & 3 & 4 & 16 & $67 \%$ \\
\hline Полина М. & 2 & 4 & 3 & 3 & 4 & 4 & 20 & $83 \%$ \\
\hline Маша М. & 4 & 4 & 4 & 3 & 4 & 3 & 22 & $91 \%$ \\
\hline Катя Р. & 4 & 3 & 4 & 4 & 3 & 4 & 22 & $91 \%$ \\
\hline Юра Р. & 2 & 3 & 2 & 3 & 4 & 2 & 16 & $67 \%$ \\
\hline Данила Р. & 3 & 3 & 2 & 3 & 2 & 2 & 15 & $63 \%$ \\
\hline Дима Т. & 4 & 3 & 3 & 2 & 3 & 4 & 19 & $79 \%$ \\
\hline Артем Т. & 2 & 2 & 0 & 1 & 1 & 0 & 6 & $25 \%$ \\
\hline Всего баллов & $\mathbf{5 3}$ & $\mathbf{5 5}$ & $\mathbf{4 5}$ & $\mathbf{5 0}$ & $\mathbf{5 5}$ & $\mathbf{5 2}$ & & \\
\hline Всего \% & $\mathbf{7 3 \%}$ & $\mathbf{7 6 \%}$ & $\mathbf{6 2 \%}$ & $\mathbf{6 9 \%}$ & $\mathbf{7 6 \%}$ & $\mathbf{7 2 \%}$ & & \\
\hline
\end{tabular}

Примечание. Обозначения интеллектуальных операций здесь и далее: Ан - анализ, С синтез, Аб - абстрагирование, Ср - сравнение, Об - обобщение, К - классификация.

отношению ко всем интеллектуальным операциям - от $21 \%$ до $96 \%$;

3) разные операции характеризуются разным уровнем рефлексии от $62 \%$ до $76 \%$.

Всех испытуемых можно разделить на 3 группы: учащиеся с высоким, средним и низким уровнем рефлексии интеллектуальных операций.

Высокий уровень рефлексии показали 66\% учащихся, средний -
17\% учащихся, низкий - также 17\% учащихся. Полученные данные представлены на рисунке 1.

В двух нижних строках таблицы 1 показано количество баллов по каждой интеллектуальной операции, набранных всеми испытуемыми и выраженных в абсолютных числах и в процентах. Результаты позволяют сделать вывод о том, что каждую из изучаемых операций дети могут 


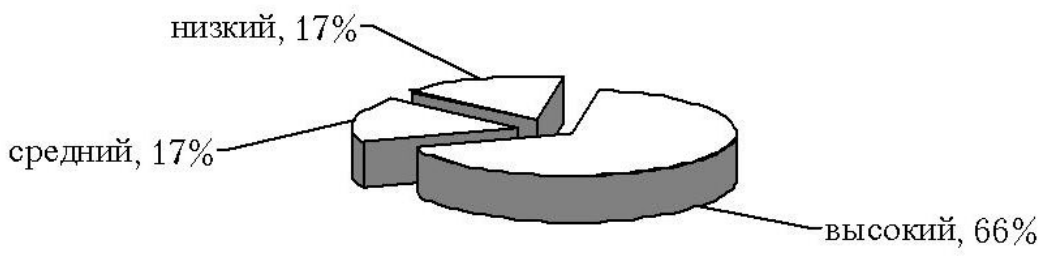

Рисунок 2

Результаты рефлексии отдельных интеллектуальных операций

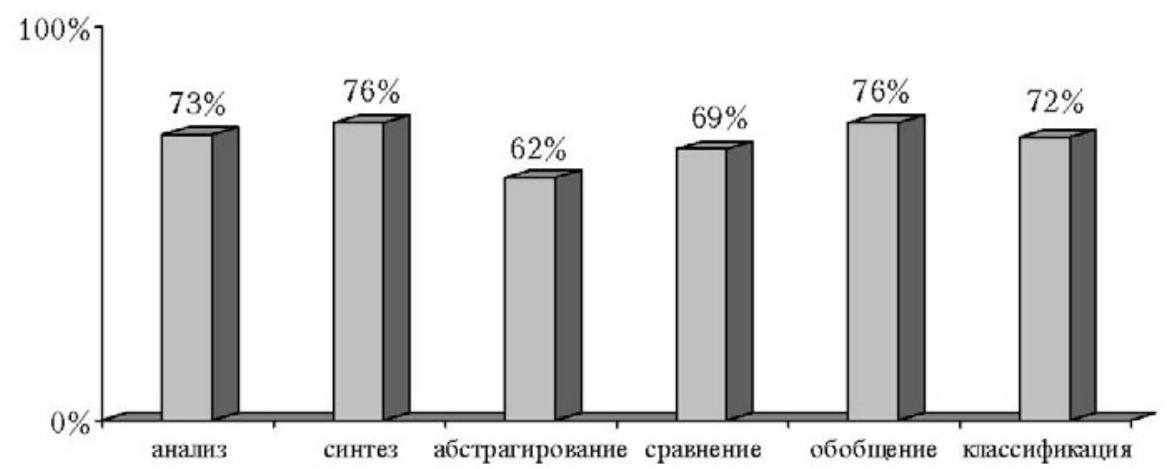

рефлексировать, но в разной мере. Согласно полученным данным, наиболее простыми для осознания оказались операции синтеза и обобщения (на них указали 76\% учащихся), средними по сложности - операции анализа (73\%), классификации (72\%), сравнения (69\%). Наиболее сложной оказалась операщия абстрагирования (62\% детей). Результаты представлены на рисунке 2.

Следующей задачей явилось выявление взаимосвязей между уровнем владения интеллектуальными операциями и их рефлексией. Полученные данные представлены на рисунке 3.

Очевидно, что уровень усвоения интеллектуальных операций выше, чем уровень их рефлексии, причем это характерно для каждой операции. Для проверки гипотезы о взаимосвязи между показателями уровня усвоения интеллектуальных операций и их рефлексии был проведен корреляционный анализ с использованием коэффициента Пирсона. Коэффициент корреляции составил $r=$ $=0.55$ с уровнем значимости $p=0.05$. Это означает, что чем выше уровень рефлексии интеллектуальных операций, тем учашийся более успешен в овладении ими, и наоборот.

Во второй серии исследований анализировалась взаимосвязь уровня рефлексивности как личностного качества и показателей рефлексии 


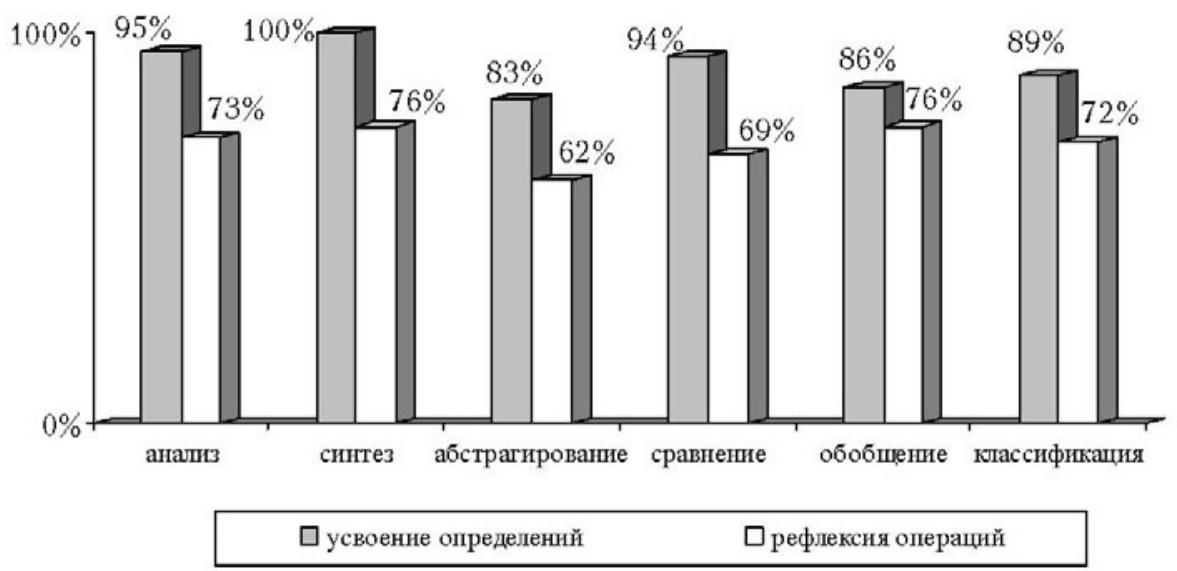

интеллектуальных операций. Для этого была использована психодиагностическая методика определения индивидуальной мерь рефлексивности А.В. Карпова и В.В. Пономаревой (Карпов, 2003, 2004).

Согласно используемой методике, показатели, равные или большие чем 7 стенов, свидетельствуют о высокоразвитой рефлексивности. Результаты в диапазоне от 4 до 6 стенов характеризуют средний уровень рефлексивности. Показатели меньше 4 стенов свидетельствуют о низком уровне развития рефлексивности. Результаты исследования индивидуальной меры рефлексивности испытуемых, участвовавших в исследовании, представлены в таблице 2 и на рисунке 4.

Bce испытуемые были разделены на 3 группы: обладающие высоким, средним и низким уровнем личностной рефлексивности. Согласно полученным данным, высоким уровнем рефлексивности обладают 39\% учащих- ся (7 человек), средним - 50\% (9 человек) и низким - 11\% (2 ученика).

Далее были сопоставлены результаты по двум методикам: авторской, направленной на установление уровня рефлексии интеллектуальных операций, и методики А.В. Карпова, определяющей меру индивидуальной рефлексивности. Проделанный анализ позволил установить наличие связи между этими двумя показателями. Результаты представлены в таблице 3.

Корреляционный анализ показал, что связь между уровнем рефлексии мыслительных операций и мерой индивидуальной рефлексивности учащихся достоверна на 1\%-ном уровне значимости $(r=0.82, p=0.01)$.

В рамках реализации программы исследования был также изучен характер взаимосвязи меры индивидуальной рефлексивности учащихся с рефлексией каждой операщии мышления в отдельности. Данные представлены в таблице 4. 
Таблииа 2

Индивидуальная мера рефлексивности учащихся

\begin{tabular}{|l|c|c|c|}
\hline Имя Ф. & Количество баллов & Количество стенов & Уровень рефлексии \\
\hline Арсений А. & 145 & 7 & высокий \\
\hline Денис В. & 137 & 6 & средний \\
\hline Лейла Г. & 142 & 7 & высокий \\
\hline Люба Г. & 128 & 5 & средний \\
\hline Дарина д. & 145 & 7 & высокий \\
\hline Дуня 3. & 126 & 5 & средний \\
\hline Габор К. & 129 & 5 & средний \\
\hline Вахтанг К. & 119 & 4 & средний \\
\hline Денис К. & 81 & 1 & низкий \\
\hline Аня К. & 152 & 8 & высокий \\
\hline Алеша М. & 138 & 6 & средний \\
\hline Полина М. & 163 & 9 & высокий \\
\hline Маша М. & 138 & 6 & средний \\
\hline Катя Р. & 150 & 8 & высокий \\
\hline Юра Р. & 146 & 7 & высокий \\
\hline Данила Р. & 129 & 5 & средний \\
\hline Дима Т. & 134 & 6 & средний \\
\hline Артем Т. & 92 & низкий \\
\hline
\end{tabular}

Уровень индивидуальной рефлексивности испытуемых

Рисунок 4

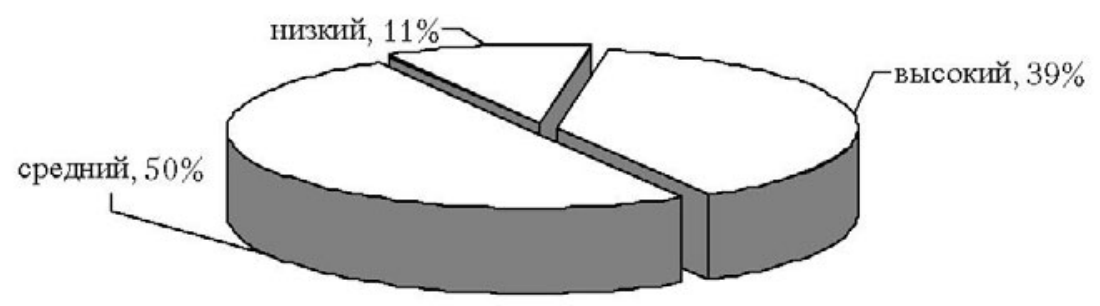

На основе данных, представленных в таблице 4, был проведен корреляционный анализ связей между баллом, характеризующим индивидуальную меру рефлексивности испытуемого, и баллами, отражающими уровень развития отдельных операций мышления.

Согласно полученным данным, корреляция между всеми представ- 
Сравнение рефлексии интеллектуальных операций и меры индивидуальной рефлексивности учащихся

\begin{tabular}{|l|c|c|}
\hline Имя Ф. & $\begin{array}{c}\text { Рефлексия интеллектуальных } \\
\text { операций, баллы }\end{array}$ & $\begin{array}{c}\text { Уровень рефлексивности, } \\
\text { баллы }\end{array}$ \\
\hline Арсений А. & 22 & 145 \\
\hline Денис В. & 16 & 137 \\
\hline Лейла Г. & 18 & 142 \\
\hline Люба Г. & 19 & 128 \\
\hline Дарина Д. & 20 & 145 \\
\hline Дуня З. & 18 & 126 \\
\hline Габор К. & 23 & 129 \\
\hline Вахтанг К. & 8 & 119 \\
\hline Денис К. & 5 & 152 \\
\hline Аня К. & 23 & 138 \\
\hline Алеша М. & 16 & 163 \\
\hline Полина М. & 20 & 138 \\
\hline Маша М. & 22 & 150 \\
\hline Катя Р. & 22 & 146 \\
\hline Юра Р. & 16 & 129 \\
\hline Данила Р. & 15 & 134 \\
\hline Дима Т. & 19 & 92 \\
\hline Артем Т. & 6 & \\
\hline
\end{tabular}

ленными в таблице 4 операциями и оценкой индивидуальной меры рефлексивности является положительной, характер зависимости - прямо пропорциональный. Степень связи между индивидуальной мерой рефлексивности и уровнем рефлексии отдельных мыслительных операций можно оценить как среднюю или сильную (диапазон коэффициентов варьируется от 0.54 до 0.79). Самые высокие показатели отмечаются для операции сравнения $(r=0.79)$ и классификации $(r=0.78)$, самый низкий - для анализа $(r=0.54)$. Уровень достоверности равен 0.01 (для операций абстрагирования, сравнения, обобщения, классификации) и 0.05 (для операций анализа и синтеза).

Проведенный анализ показывает, что уровень индивидуальной рефлексивности проявляется в освоении всех интеллектуальных операций. Эмпирическое исследование позволило установить, что рефлексивность как личностная характеристика имеет ярко выраженные линейные взаимосвязи с рефлексией интеллектуальных операций.

Таким образом, наше экспериментальное исследование подтверждает 